\title{
MICROBIAL PRODUCTION OF 2,3- BUTANEDIOL FROM WASTE GLYCEROL
}

\author{
S. Yankova \\ P. Begova \\ V. Beschkov \\ Institute of Chemical Engineering, Bulgarian Academy of Sciences, Bulgaria
}

\begin{abstract}
An inevitable waste from biodiesel production is glycerol, contaminated by alkaline catalyst, water and methanol and released in quite big amounts, exceeding its market demand. One way of its utilization is production of different bulk and fine chemicals, for example 2,3butanediol. The latter is used as a precursor for manufacturing of plastics, synthetic rubber, some pharmaceuticals, etc.

In the present paper the ability of the strain Klebsiella oxytoca VA 8391 to produce this compound under batch and fed-batch conditions was studied at initial glycerol concentrations between 10 and $30 \mathrm{~g} \mathrm{dm}^{-3}$.

Experiments have been carried out in shaking flasks. The bacteria cultivation was at $37^{\circ} \mathrm{C}$ and stirred conditions at $200 \mathrm{rpm}$, whereas the product formation was studied both under stirred and still conditions. It was found out that the used strain is capable to produce selectively 2,3butanediol with very high yields of practical importance (up to $92 \%$ ) and no contamination by other products. The optimum glycerol concentration was $20 \mathrm{~g} \mathrm{dm}^{-3}$. At higher initial concentrations substrate inhibition started to occur.

It was established that the studied fermentation process required aerobic bacteria cultivation followed by anoxic period of product formation by the developed culture. Only in this case high yields were attained.
\end{abstract}

\section{KEYWORDS}

Glycerol utilization; microbial process, Klebsiella oxytoca; 2,3-butanediol production;

\section{INTRODUCTION}

Glycerol as a by-product of biodiesel production is becoming a cheap and abundant substrate for bioconversion. In fact, there is an urgent need to find new practical applications for glycerol. Glycerol can be converted into a number of industrially valuable fine and bulk chemicals by chemical or biotechnological methods. At current prices, glycerol is very competitive with sugars used in the production of chemicals and fuels via microbial fermentation [1]. Such chemicals produced by biotechnologies are mainly 1,3-propanediol, 1,2-propanediol, 2,3-butanediol, dihydroxyacetone, polyglycerols, succinic acid, and various polyesters, used as biodegradable constituents of packaging. Examples for such polymers are the poly-hydroxyalkanoates (e.g. butyrates, valerates, lactates, etc.) [2]. As a whole, glycerol can replace oil as a raw material for various organic syntheses. Two very important polyols, produced from glycerol are 1,3-propanediol and 2,3-butanediol. 1,3-Propanediol is recently 
applied for production of polypropylene terephthalate as a component of biodegradable packaging requiring a drastic increase in the production of this chemical [3].

Butanediols can be used in synthetic rubber manufacturing [4,5], solvents production and as a fuel additive too [6].

The main drawbacks in the microbial processes for 1,3-propanediol and 2,3-butanediol production is the low yield and the complicated reaction mixture resulting from the fermentation process [7]. In the present paper an attempt to produce solely 2,3-butanol from glycerol with sufficiently high yield is made. For this purpose the strain Klebsiella oxytoca VA 8391 was used under aerobic conditions. It was supposed in this way to avoid 1,3propanol formation and to enhance the process selectivity.

\section{MATERIALS AND METHODS}

\subsection{Strain.}

The strain Klebsiella oxytoca VA 8391 was used in our study. The inoculation medium was (in g): meat extract, 1.0; peptone, $1.0 ; \mathrm{NaCl}, 0.5$; distilled water, $100 \mathrm{ml}$. The medium acidity was adjusted to $\mathrm{pH}$ 7.2-7.4. The working medium contained (in g/l): glycerol, 10-30; $\mathrm{MgSO}_{4} .7 \mathrm{H}_{2} \mathrm{O}, 0.2 ; \mathrm{CaCl}_{2} .2 \mathrm{H}_{2} \mathrm{O}, 0.2$; "salt medium" 25 ; phosphate buffer for $\mathrm{pH}$ 7.0. The "salt medium" contained (mg/l): $\mathrm{CaCl}_{2} .2 \mathrm{H}_{2} \mathrm{O}, 2.5 ; \mathrm{FeSO}_{4} .7 \mathrm{H}_{2} \mathrm{O}, 1 ; \mathrm{ZnSO}_{4} .2 \mathrm{H}_{2} \mathrm{O}, 0.05$; $\mathrm{H}_{3} \mathrm{BO}_{3}, 0.05 ; \mathrm{CoCl}_{2} .6 \mathrm{H}_{2} \mathrm{O}, 0.02 ; \mathrm{Na}_{2} \mathrm{MoO}_{4} .2 \mathrm{H}_{2} \mathrm{O}, 0.015 ; \mathrm{NiCl}_{2} .6 \mathrm{H}_{2} \mathrm{O}, 0.02$.

All media were preliminary sterilized before inoculation.

The strain was kept on inclined agar slants at $4^{\circ} \mathrm{C}$. The agar medium had the content of the inoculation medium with $20 \mathrm{~g} / \mathrm{l}$ agar. The strain was cultivated for 24 hours in rotary shaker, a New Brunswick Scientific production at $200 \mathrm{rpm}$ at $37^{\circ} \mathrm{C}$. After development the culture was supplied with glycerol. The experiments on 2,3-butanol production were carried out in shaking flasks too.

\subsection{Materials}

Besides the salts listed above pure anhydrous glycerol was added to attain initial concentrations from 10 to $30 \mathrm{~g} / \mathrm{l}$. When fed-batch processes were studied the attained concentrations were between 5 and $10 \mathrm{~g} / \mathrm{l}$.

\subsection{Batch processes}

Two strategies for batch processes were studied: one, with continuous shaking and aeration and one with stopped shaker when the culture was completely developed. In the second phase in quiescent medium the aeration rate was considerably lower and anoxic conditions in the broth took place.

\subsection{Analyses}

The taken samples were filtered and analyzed for 2,3-butanol, 1,3-propanediol and glycerol by HPLC. For this purpose a liquid chromatograph Perkin Elmer Series 10C with RI detector coupled with Bio-Rad column for organic acid analysis (Aminex ion exclusion HPX-87H) at $65{ }^{\circ} \mathrm{C}$. As a mobile phase, a $0.01 \mathrm{~N}$ sulfuric acid at flow rate of $0.6 \mathrm{ml} / \mathrm{min}$ was used. For qualitative identification standards of 1,3-propanediol and 2.3-butanol were used.

The biomass content was assayed by its optical density.

\section{RESULTS AND DISCUSSION}


All of our results show that 2,3-butanediol was selectively produced. No 1,3-propanediol was detected in the samples as iy is demonstrated on the HPLC-chromatogram, shown in Figure 1.

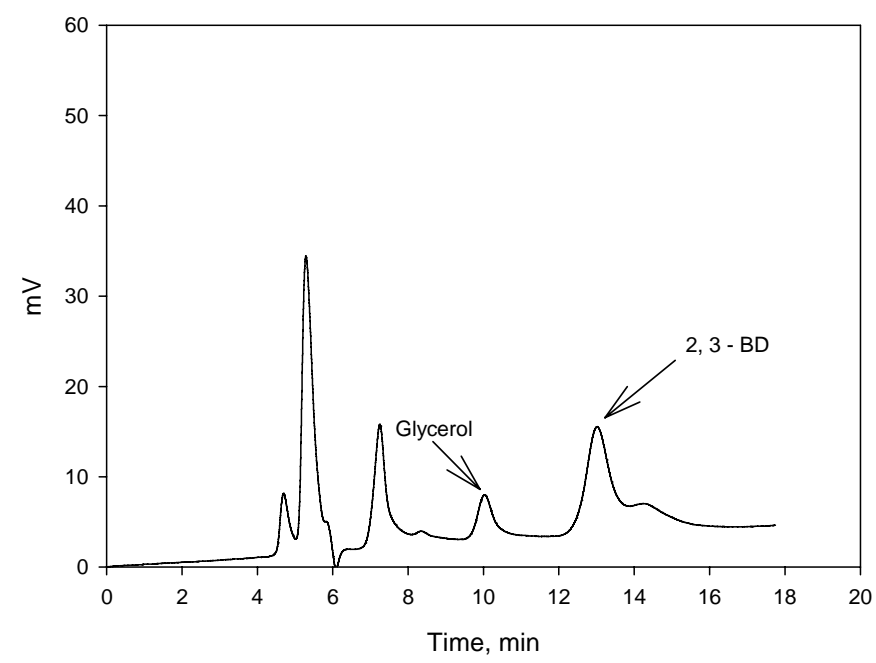

Figure 1. HPLC-chromatogram of fermentation broth. The peaks in the beginning are of inert compounds contained in the cultivation media.

The 1,3-propanediol peaks appears at the $12^{\text {th }}$ minute, i.e. there is no such a product in the broth. One could expect it, because the latter is specific product of the reductive pathway of glycerol digestion by the Klebsiella strains, see Scheme 1 [8]. However, the concentrations of 2,3-butanediol and the corresponding yields remained too low, reaching $25 \%$ molar yield, see Figure 2. There is a study on similar process [9], carried out with the strain Klebsiella pneumoniae G31 at much higher initial glycerol concentrations (up to $140 \mathrm{~g} / \mathrm{l}$ ) showing higher results for 2,3-butanol with molar yields, reaching 49\%, but with significant content of 1,3propanediol (7-40 g/l) and small amounts of ethanol $(14 \mathrm{~g} / \mathrm{l})$ and organic acids: lactic, succinic, acetic ones.

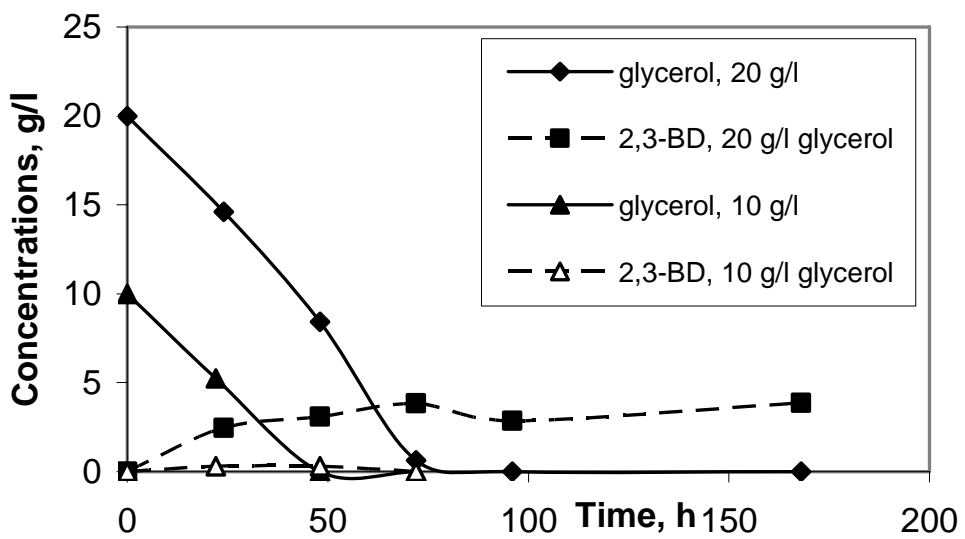

Figure 2. Experimental data for 2,3-butanediol production from glycerol at two initial concentrations.

When in our study the initial concentration of glycerol was $30 \mathrm{~g} / 1$ the process was slowed down up to 180 hours with a molar yield of $17 \%$. 
Our best and most interesting results were attained when the shaking and the aeration were stopped after the culture development. In this case we attained very high 2,3-butanediol concentration with high yield and selectivity, see Figure 3. We succeeded to attain $16 \mathrm{~g} / \mathrm{l}$ of

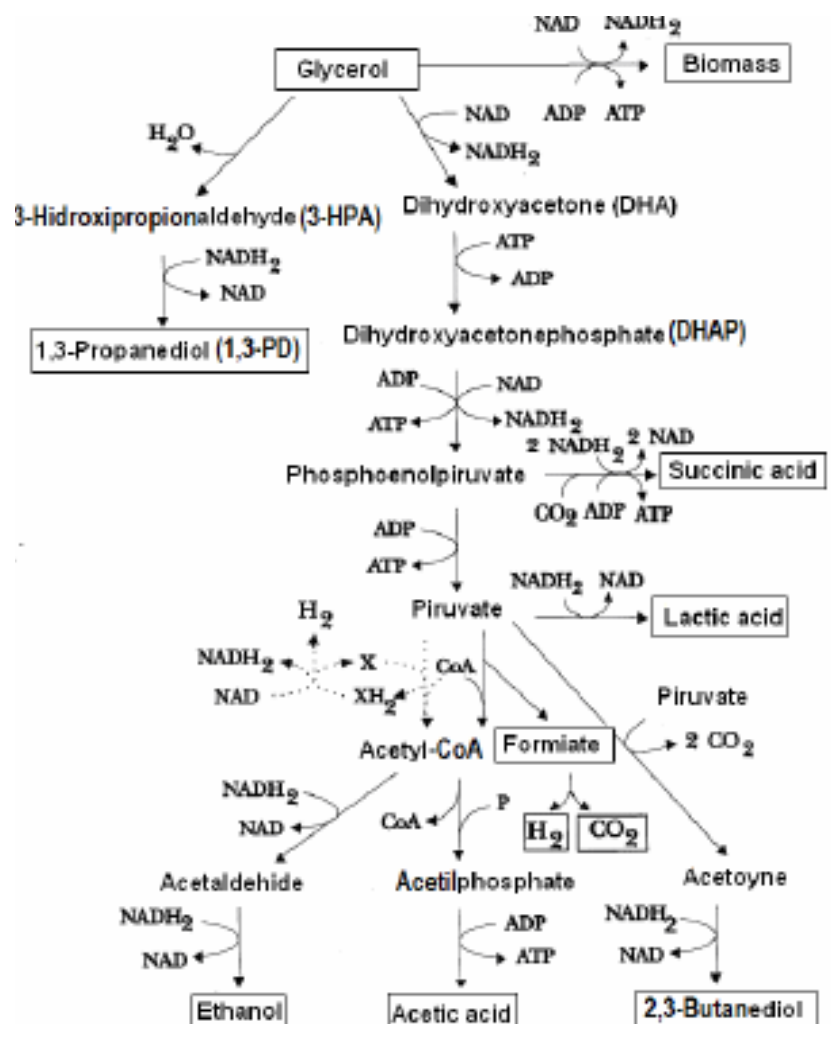

Scheme 1. Anaerobic glycerol metabolism in Klebsiella sp. [8].

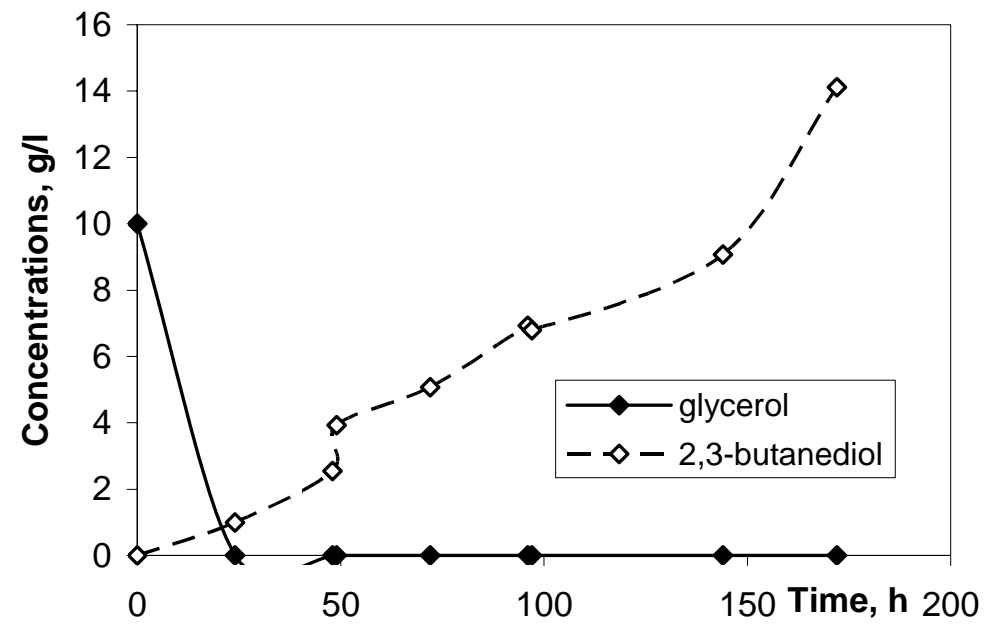

Figure 3. Experimental data for 2,3-butanediol production from glycerol at anoxic conditions.

2,3-butanol with a molar yield of $82 \%$. No 1,3-propanediol or other alcohols were detected in the broth, cf. the chromatogram in Fig. 3. How can we explain this effect? First, the aerobic 
conditions prevent the cells to follow the reductive pathway to produce 1,3-propanediol. On the other hand the shortage of oxygen during the second phase may be makes the 2,3butanediol production more attractive than the production of organic acids - lactic, succinic and acetic ones. These speculations will be confirmed or rejected after following the metabolic pathway for the strain and trying to identify the intermediates during the fermentation process.

This will be the goal of our next experiments to complete our research.

\section{ACKNOWLEDGEMENT}

This study is supported by Grant DTK-36/2009 of the National Fund for Scientific Research of Republic of Bulgaria.

\section{REFERENCES}

[1] da Silva, G.P., Mack, M., Contiero, J., 2009. Glycerol: A promising and abundant carbon source for industrial microbiology, Biotechnol. Adv., 27, 30-39

[2] Ashby, R.D., Wyatt, V.T., Foglia, T.A., Solaiman, D.K.Y., 2009. Industrial products from biodiesel glycerol, in: Biocatalysis and Bioenergy (Ching T. Hou, Jei-Fu Shaw, editors), J. Wiley\&Sons Inc., Hoboken, N.J., pp. 131-149.

[3] González-Pajuelo, M., Meynial-Salles, I., Mendes, F, Soucaille, P., Vasconcelos I., 2006. Microbial conversion of glycerol to 1,3-propanediol: physiological comparison of a natural producer, Clostridium butyricum VPI 3266 and an engineered strain, Clostridium acetobutylicum DG1 (pSPD5). Appl. Env. Microbiol., 72, 96-10

[4] Garg, S.K., Jain, A., 1995. Fermentative production of 2,3-butanediol: a review. Bioresource Technol., 51, 103-109.

[5] Syu, M.J., 2001. Biological production of 2,3-butanediol. Appl. Microbiol. Biotechnol., $55,10-18$.

[6] Wu, K.J., Saratale, G.D., Lo, Y.C., Chen, W.M., Tseng, Z.J., Chang, M.C., Tsai, B.C., Su, A., Chang, J.S., 2008. Simultaneous production of 2,3-butanediol, ethanol and hydrogen with a Klebsiella sp. strain isolated from sewage sludge. Bioresource Technol., 99, 79667970.

[7] Xiu, Z.L., Zeng, A.P., 2008. Present state and perspective of downstream processing of biologically produced 1,3-propanediol and 2,3-butanediol. Appl. Microbiol. Biotechnol., 78, 917-926.

[8] Zhang, Y., Huang, Zh., Du, Li Y., Cao, Z., 2009. Introduction of an NADH regeneration system into Klebsiella oxytoca leads to an enhanced oxidative and reductive metabolism of glycerol, Metabolic Eng., 11, 101-106.

[9] Petrov, K., Petrova, P., 2009. High production of 2,3-butanediol from glycerol by Klebsiella pneumoniae G31, Appl. Microbiol. Biotechnol., 84, 659-665. 


\title{
A STRUCTURED LITERATURE SURVEY ON LANFILL MINING
}

\author{
Amit Shankar Ranjit \\ Linköping University, Sweden
}

\begin{abstract}
Landfilling is a traditional method to dispose waste materials from the society. Negative environmental impacts and waste material that could turn into resource are two main issues associated with landfills. Landfill mining is one of the proposed strategies to solve the problems and to benefit from the potentials linked to landfills. Definition of landfill mining is deficient.

This article is a summary of the author's master's thesis which aimed to perform a structured literature survey to identify the knowledge level of landfill mining, identify future research areas and define landfill mining. The structured methodology for the literature surveys was implemented. 68 articles were finally selected and categorized into three themes: societal metabolism, landfill mining pilot studies and implementation studies.

Conclusions made were that landfill mining is not yet defined in a concrete manner and it is very important to integrate into it the holistic perspective offered by material flow studies. Research trend shows that the number of scientific reports on material flow studies and landfill mining is increasing and they all agree that landfill mining is viable option in waste management strategy, but with plenty of obstacles and future research needs. A systems approach is needed in order to evaluate the potentials of landfill mining and to deal with the management and organization of complexities. The material flow studies are not the motivation behind mining landfills. There is a need for the tools to identify profitable landfills. Methods and tools to characterize and quantify the waste require further development. Further researches on technology are recommended. The economic analysis models and environmental and business models need to be tested broadly. High-level policymaking is essential to promote landfill mining.
\end{abstract}

\section{KEYWORDS}

Landfill mining; Urban mining; Resource recovery; Landfill reclamation; Structured literature survey; Material flow studies; Waste characterization.

\section{INTRODUCTION AND AIM}

Lanfilling is a traditional method to dispose waste materials from the society. A rapid population growth and a strong economic development have given rise to tremendous amount of waste generation that need to be taken care of. There are two main environmental implications associated with landfills: environmental problems and resource aspect.

Landfill mining is a proposed strategy to solve the problems and realize the potentials linked to landfills. It is defined as the practice of excavation, processing, treatment and/or recovery of the materials that throughout the years have been dumped in waste deposits. However, the 
objectives have differed largely depending upon the contexts of the projects. Several such objectives have been identified from different definitions of landfill mining. This means that landfill mining is not defined in a concrete manner which creates the dilemma about its meaning and aim. In this context, it is quite essential to know how the research in this topic has been carried out during the years. This will help to identify the future research areas.

The aim of this thesis is to perform a structured literature survey in order to identify the present knowledge level of landfill mining. The focus will be on how landfill mining is defined and whether these definitions could be improved; topics addressed and research trends; contributions of landfill mining research and future research needs.

\section{THEORETICAL PERSPECTIVE}

This paper has been written with two theoretical perspectives of industrial ecology and resource stocks and reservoirs. Industrial ecology is the 'science of sustainability [1]' that applies holistic views on material and energy flows. Since the notion of waste is central to industrial ecology literature [2], they suggest that there is a potential to convert waste outputs into resource inputs. Industrial ecology also provides a framework for the business opportunities coming from production and waste generation. According to White, the objective of industrial ecology is to learn ways to integrate environmental concerns into the economic activities [3].

The theories of resource stocks and reservoirs serve as a guide to the development context of landfill mining. Resources do not exist only in the earth's crust but also as material stocks accumulated in the technosphere. Kapur and Graedel argue that such technospheric stocks will become important resource reservoirs in the future [4]. They have developed a typology for resource stocks, dividing them into geochemical, employed and expended reservoirs. The expended reservoir, which includes deposited stock, is pertinent to landfill mining. Deposited stock is the amount of material accumulated in reservoirs such as landfills and tailing ponds. Kapur and Graedel have termed the deposited stock, 'technospheric mine' for two reasons: the location of the resource is known and as rich in ore as geochemical ore stock [4].

\section{METHODOLOGY}

This is an extensive survey of the scientific literature relevant to landfill mining. The guideline of structured methodology for literature surveys developed by Ram et al. was used for the purpose [5]. However, this methodology was slightly modified in order to fit the scope of the study (see Figure 1). The structured methodology for literature surveys follows a six step procedure [5].

The reference lists of the articles selected in the third step were used in order to obtain additional studies on landfill mining (see Figure 1). Finally 68 papers were selected for the detailed study. They are categorized into three themes: societal metabolism, landfill mining pilot studies and implementation studies. The major task of the project was to read in detail the selected literature and analyze its content. Various tools were employed to construct the framework for the analysis. 


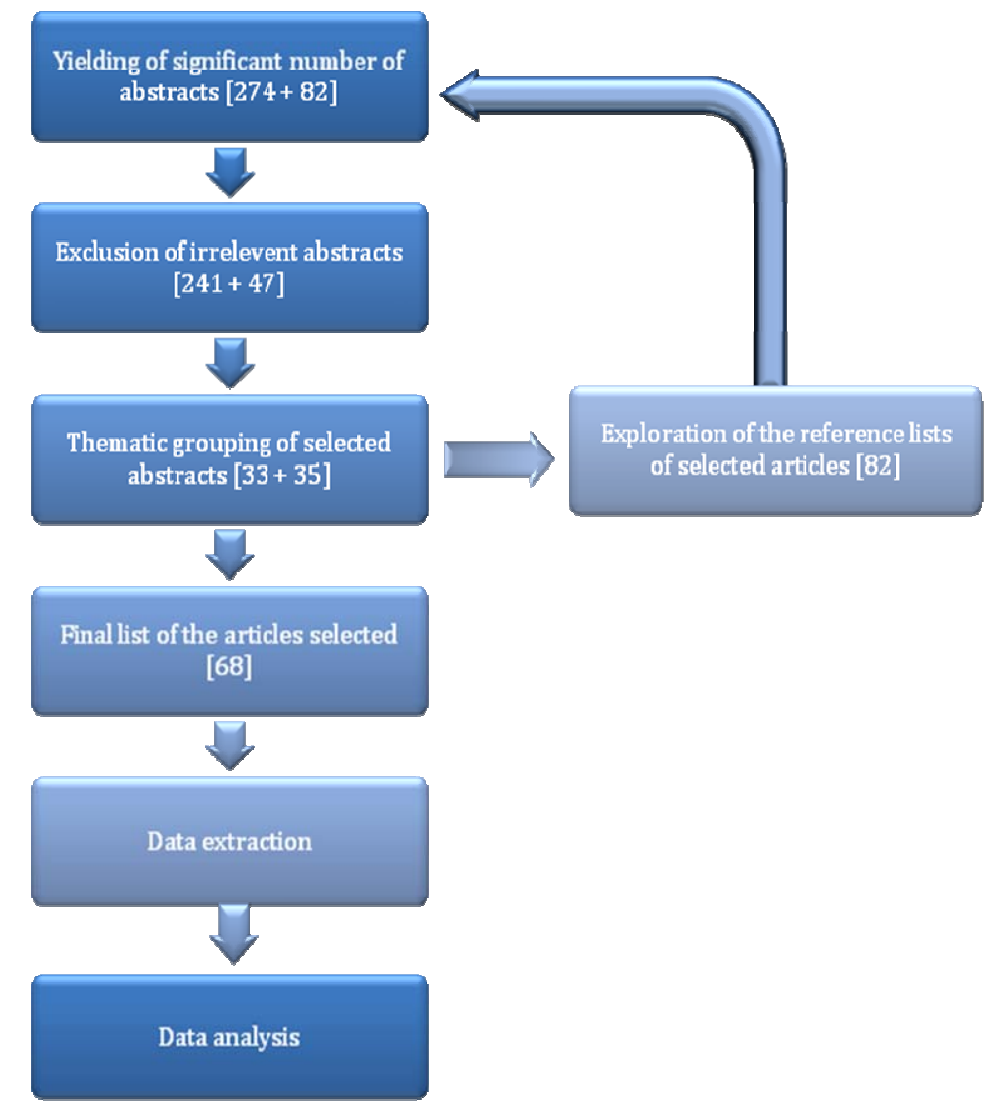

Figure 1. Structured methodology of literature survey; also includes number of articles selected at different steps.

\section{RESULTS}

\subsection{Research trend in landfill mining}

The research trends of the three identified themes of studies are illustrated (see Figure 2). After 2000, a significant increase in research articles on material flows can be observed. These articles illustrate that landfills have potential to be a major resource mine. They have quantified the amount of materials located in different kinds of reservoirs and landfills contain large portion of valuable material. A similar trend can be seen for the scientific reports on landfill mining studies after 2000. However, during the middle of the 1990s, many feasibility studies on landfill mining were published. These articles provide the details on feasibility of landfill mining addressing waste characterization and technological efficiency of landfill mining. On the other hand, articles on landfill mining implementation follow a different trend. Such articles are not published recently. The implementation studies and reports are mostly seen from 1995 to 1998. 


\subsection{Addressed topics within each research theme}

\subsubsection{Material flow studies:}

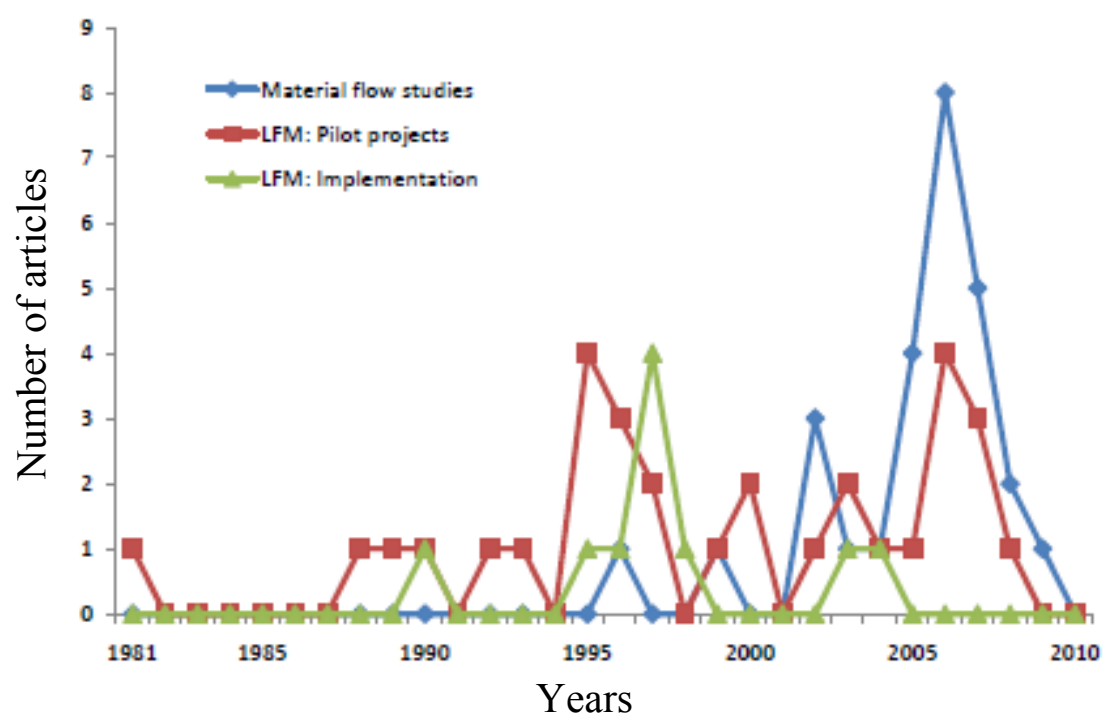

Figure 2. Number of selected research papers on material flow studies; Publication trend of research project reports on landfill mining; Publication trend of project reports on implementation of landfill mining.

The material flow studies focus on the potential recovery of metals from the resource reservoirs such as landfills. Landfills are a non-steady reservoir because annual inflow exceeds outflow [6]. Daigo et al. identified landfills as a kind of stock with some potential for resource recovery [7]. These studies are especially focused on the flows of metals such as copper, iron, zinc, silver, lead and chromium. The articles have quantified the amount of metals discarded into and located in the landfills. These studies show that different metals are discarded in landfills in varying proportions and there are significant spatial differences in these distributions. However, there are a number of barriers which could make landfill mining difficult from an economic perspective.

\subsubsection{Landfill mining:}

Contents of the landfills, technological sorting efficiency and economic aspects of landfill mining are the main focuses. Waste characterization is identified to be a critical phase. Hogland recommended the investigations on waste characterization prior to full-fledged landfill mining projects [8]. Analysis of wastes is to be carried out for different parts and layers of the landfills in order to identify the heterogeneity of the waste. Nature and composition of waste could also be observed during the excavation of the landfills [8].

Savage et al. discussed the procedures and technology [9]. A basic and a complex landfill mining operations (see Figure 3(a) and (b)) have been put forward [9]. Some articles listed out the equipments [9, 10, 11]. Literature available for landfill mining technology and procedures can be categorized as pre-excavation and post-excavations phases. Besides, many articles have made observations on economics of landfill mining activity. 


\subsubsection{Implementation studies:}

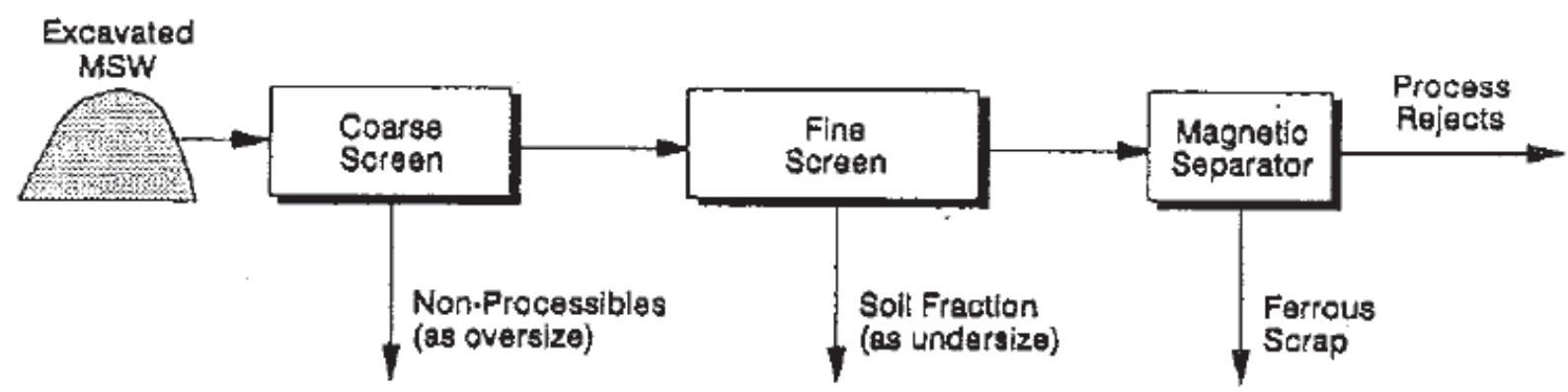

(a)

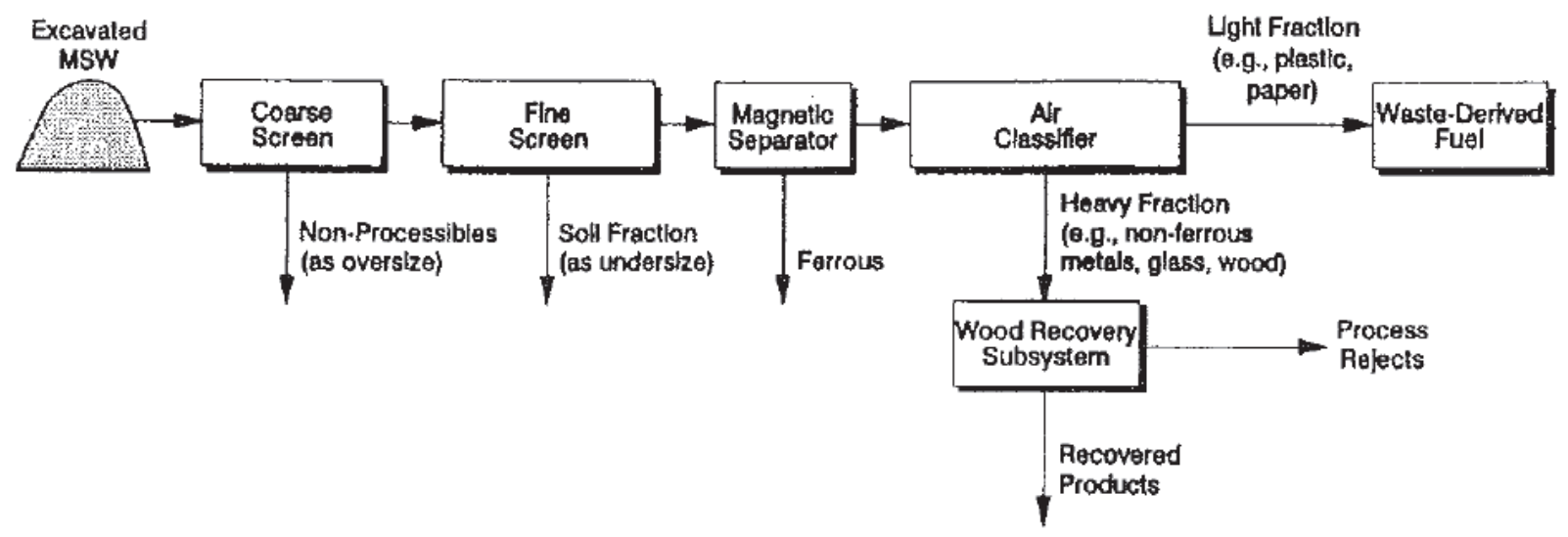

(b)

Figure 3. (a) Basic landfill mining operation [9], (b) Complex landfill mining operation [9]

Most of the landfill mining efforts were found to be pilot and research projects in Europe until 1996, whereas it was done on a commercial basis in the USA [12]. There were about 40 landfill mining projects at the different stages of the implementation in USA and Canada [13]. Some of them were landfill reclamation projects in Florida, New York and Pennsylvania in the USA offering extended landfill life, material recovery and landfill footprint reduction [11]. Landfill mining and remediation works were carried out at twin landfill sites in Ulsan, Korea [14]. One landfill site was mined and turned into a useful land, while second was considered for remediation. In North Carolina (USA), construction and demolition waste were mined and recycled to restore the landfill capacity and thus, avoiding new landfill sites [15].

The factor of success or failure behind landfill mining is the economic performance it generates. Fisher and Findley explored the economic aspects of landfill mining [16]. They observed that economics involved in the landfills depend upon their unique circumstances. One way to determine economic viability of landfill mining would be considering it in the context of overall solid waste management costs and not just evaluating against conventional closure. van der Zee et al. brought up an interesting issue of companies operating landfills [17]. The decreasing trend in an amount of waste disposal into the landfill led to the shrinking of market size for those companies. So, landfill mining could be the alternative business strategy for them. But they lack the method to efficiently find the most profitable landfills. A stepwise research method was proposed in order to save time and cost to select potentially most marketable landfills. 
Public concerns and scarce landfill space were driving the policy-makers towards sustainable waste management practices. Policy-makers and regulators were required to agree upon carrying out pilot projects to discover the potentials of mining landfills [18]. In order to prevent the future emissions and meet the demand of EU Waste Council Directive, landfill mining would be one option for remediation ventures [8]. According to Reith and Salerni, 'the project must be planned and implemented in compliance with a complex array of laws, regulations and ordinances pertaining to resource development, remediation, occupational safety, land use and protection of air and water quality' [19].

Environmental issues were not considered as a major topic of discussion. A single paper had appeared in the search whose major focus was the construction of model for environmental assessment [20]. Other numerous articles had brought up an environmental issues but only as a part of a discussion. Here environmental problems arising from landfill mining would not be confused with that from landfills.

Some environmental concerns found in literatures were particularly leachate generation, micro-organisms, gas release, odor problem, hazardous waste, noise, dust, fires, explosions and so on $[12,13,21,22]$. Cossu et al. did not find any operational environmental problems during an excavation in one of the Swedish landfills [12]. No dust or flies were detected while there was a mild odor problem. Hazardous waste was properly handled. Cobb and Ruckstuhl also concluded that there were no environmental and safety hazards from mining activities [10]. Cossu et al. stressed on future research on environmental effects and safety issues despite no immediate risks predicted [12]. This would be essential to satisfy stakeholders. Environmental impacts assessments should be conducted before mining particularly for remediation of contaminated land and regarding risks of ground and surface water pollution $[23]$.

\subsection{Definitions of landfill mining}

First of all, literatures which have attempted to define landfill mining were considered. Not all of the selected literatures tried to specifically define landfill mining. It is evident (see Figure 4) that the most focussed issues in landfill mining were landfill reclamation and materials recovery, particularly soil and refuse-derived fuel.

\section{DISCUSSION}

\subsection{Defining landfill mining}

It could be seen from the results obtained that no standardised definition of landfill mining is followed. Landfill or land reclamation avoiding closure is a primary focus, whereas material recovery is meant for landfill cover and waste fuel. The definitions differ from article to article depending upon the context of the study. Considering landfill mining from a local or single perspective will delimit its potential. So it is essential that landfill mining is defined in a way that would make its realization possible in the future. More importantly, landfill mining can only be defined integrating various issues considered above. One definition could be proposed:

"Landfill mining is a process of recovery of resources residing in the landfills applying advanced technologies, thereby providing various benefits." 


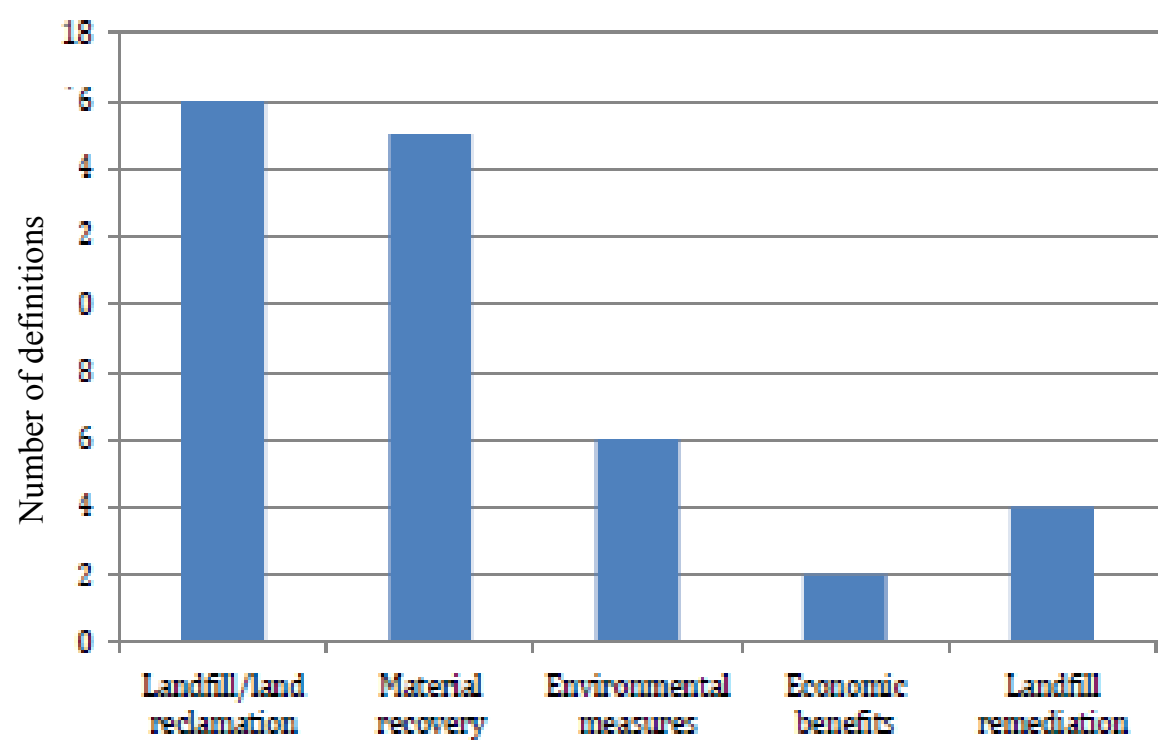

Figure 4. Focuses reflected in Landfill mining definitions

Here 'process' means the activities such as excavation, screening, processing, treatment, etc. 'Resource' means various materials which are of higher value and should not include soil, paper, plastics or wood. 'Recovery' would globally contribute to resource and environmental facets. 'Advanced technologies' would stand for the technologies which exist or still to be developed which could make economic recovery of more than one valuable material possible from the complex composition of the municipal solid wastes. 'Various benefits' means landfill mining resulting in land reclamation, local environmental solution, site redevelopment and also the use of materials such as paper, plastics or soil for secondary purposes.

\subsection{Topics addressed by landfill mining research}

Material flow studies identify the undoubted potential for resource recovery from landfills amidst the looming scarcity of many valuable materials but there are many obstacles which may prevent the development of landfill mining. Waste characterization studies are common among the landfill mining research. The researchers are interested particularly in soil recovery or recovery of material with high calorific value. Even within a single landfill, waste is heterogeneously distributed and waste characterization in one part of landfill does not represent the whole landfill. Therefore, these studies are not sufficiently convincing to start full-fledge mining of landfills.

Most important issue with the technology is that to what extent the pure material could be recovered efficiently. Though one metal could be dominant in particular landfill, it could not be denied that other metals too exist and not recommended to be wasted by focusing on dominant metal. It has been recommended to perform cost-benefit analyses before starting landfill mining, but it is not easy if all the factors are incorporated in it. Including avoided costs, social and environmental costs in the analysis could make landfill mining far more beneficial. On the other hand, the economic return from potential recovery of metals of higher value could not be denied. 
Some articles report that there are no environmental and safety hazards from landfill mining activities while other are concerned with potential hazards. These conclusions were based on the research projects. But since potential hazards may differ depending upon the way of landfilling and types of waste, it cannot be said with certainty about the consequences. Detailed Environmental Impact Assessments are necessary for different cases which would contribute in formulating general opinions. Broader implementation of landfill mining is not possible with few institutions engaging in it. Government level intervention is necessary with several organizations working in tandem to make its realization possible. The policy to mine landfill needs to be guided by the material flow studies. Research and development efforts should be encouraged.

\subsection{Contribution of landfill mining research and future research needs}

None of the papers was considering material flow studies in initiating landfill mining. However, the scientific reports on material flow studies regards landfill as an important resource reservoir. Looking into the typology of resource stocks and reservoir described earlier, attention should be given towards the 'deposited' stocks which include landfills. Recycling landfills will isolate the mines from the material flow chain and contribute towards closing the material loop. Joseph et al. suggested that landfilling would not be considered as final waste-disposal strategy but as a large-scale waste processing method [24]. Need for improved technology [25], accurate quantification [26], development of method and tools [27], policy development [28] and model with economic analysis [29] are some recommendations offered by material flow studies.

On the other hand, even in case of material flow studies' ability to answer the question of amount of metal dumped in the particular landfill, it is essential that other secondary material such as soil and plastics be recovered and utilized. The waste characterization studies would thus be essential to anticipate the market for these materials of lesser value. More research on technology to recover multiple metals with marketable purity in a single throughput is recommended.

In a bigger perspective, the studies of societal metabolism should form a basis for research and tests on landfill mining while the pilot projects should steer the broad implementation of landfill mining. The implementation should be placed at the core of the activity. Increased implementations of landfill mining will be the function of research efficiency. The study projects will always drive the society and stakeholders to consider landfill mining as a beneficial activity in socio-economic and environmental fronts. Rational studies on material flows, quantification, technology, environmental and economic applications, regulatory standards and sustainability issues will be essential. Further extensive and integrated research on landfill mining is recommended in cooperation with societal metabolism studies and sustainability policy studies.

\section{CONCLUSIONS}

The reviewed definitions reflect that the focuses of landfill mining are landfill volume reclamation and recovering materials of lesser value. However, the definitions vary from article to article. It is essential to redefine landfill mining in order to integrate into it the holistic perspective on resource conservation offered by the material flow studies. The main topics addressed by landfill mining research are waste characterization, procedures and 
technology, economic aspects, policy and regulatory and local environmental and safety issues.

Not much effort has been put to determine economic performance of landfill mining. Waste characterization studies were not conclusive when quantifying the different types of waste in landfills. Landfill mining technology is similar to that of conventional mining and alternative approach should be encouraged. Policy for landfill mining is not clear and no specific research exists to discuss regulatory issues. Environmental and safety risks are thought to be nominal, but comprehensive reports on these issues are not available. The focus, hitherto, is on local pollution issues. Most of the research papers on landfill mining follow an increasing trend whereas plenty of articles on material flows are available after 2000. Every article agrees that landfill mining is viable option in waste management strategy, but with plenty of possible obstacles and future research needs. The existence of complexities and obstacles in most of the aspects of landfill mining means that a systems approach is needed in order to evaluate the potentials of landfill mining and that deal with the management and organization of complexities.

The material flow studies are not the motivation behind mining landfills. There is a need for the tools to identify the landfills which could be profitable to recover valuable material. Methods and tools to characterize waste require further development. The economic analysis models are not broadly tested. Further researches on technology are recommended. Environmental and business models need to be formulated. Broader policy-making is essential to promote landfill mining.

\section{REFERENCES}

[1] Allenby, B.R. 1999, Industrial Ecology: Policy Framework and Implementation. Englewood Cliffs, NJ: Prentice Hall.

[2] McManus, P. \& Gibbs, D. 2008, "Industrial ecosystems? The use of tropes in the literature of industrial ecology and eco-industrial parks", Progress in Human Geography, vol. 32, no. 4, pp. 525-540.

[3] White, R.M. 1994, Preface, The greening of industrial ecosystems, edited by B. R. Allenby and D. J. Richards. Washington, DC: National Academy Press.

[4] Kapur, A. \& Graedel, T.E. 2006, "Copper mines above and below the ground", Environmental Science and Technology, vol. 40, no. 10, pp. 3135-3141.

[5] Ram, M.B., Campling, N., Grocott, P. \& Weir, H. 2008, "A methodology for a structured survey of the healthcare literature related to medical device users", Evaluation, vol. 14, no. 1, pp. 49-73.

[6] Spatari, S., Bertram, M., Gordon, R.B., Henderson, K. \& Graedel, T.E. 2005, "Twentieth century copper stocks and flows in North America: A dynamic analysis", Ecological Economics, vol. 54, no. 1, pp. 37-51.

[7] Daigo, I., Hashimoto, S., Matsuno, Y. \& Adachi, Y. 2009, "Material stocks and flows accounting for copper and copper-based alloys in Japan", Resources, Conservation and Recycling, vol. 53, no. 4, pp. 208-217.

[8] Hogland, W. 2002, "Remediation of an old landsfill site: soil analysis, leachate quality and gas production.", Environmental science and pollution research international, vol. Spec No 1, pp. 49-54.

[9] Savage, G.M., Golueke, C.G. \& von Stein, E.L. 1993, "Landfill mining. Past and present", Biocycle, vol. 34, no. 5, pp. 58-61.

[10] Cobb, C.E. \& Ruckstuhl, K. 1988, "Mining and reclaiming existing sanitary landfills.", pp. 145. 
[11] United States Environmental Protection Agency (USEPA), July 1996, "Landfill Reclamation", Solid Waste and Emergency Response.

[12] Cossu, R., Hogland, W. \& Salerni, E. 1996, Landfill Mining in Europe and USA, ISWA Year Book, pp. 107-114.

[13] Krogmann, U. \& Qu, M., 1997, "Landfill mining in the United States". Proceedings Sardinia'97, 6th International Landfill Symposium, Cagliari, vol IV, pp 543-552.

[14] Cha, M.C.,Yoon, B.H., Sung, S.Y.,Yoon, S.P., Ra, I.W., 1997, "Mining and Remediation Works at Ulsan Landfill Site", Korea. Proceedings Sardinia 00, Sixth International Landfill Symposium, Sardinia, Cagliari, vol IV, p 553-558.

[15] Chang, S. \& Cramer, R. 2003, "The potential for reduction of landfill waste by recycling and mining of construction and demolition waste at the White Street Landfill, Greensboro, North Carolina", Journal of Solid Waste Technology and Management, vol. 29, no. 1, pp. 42-55.

[16] Fisher and Findlay, 1995, "Explore the economics of landfill mining", World Wastes, vol. 38, no. 7, pp. 50-50.

[17] Van Der Zee, D.J., Achterkamp, M.C. \& De Visser, B.J. 2004, "Assessing the market opportunities of landfill mining", Waste Management, vol. 24, no. 8, pp. 795-804.

[18] Hylands,K., 1998, "Minesweeping", Surveyor, no. 5487, pp. 14-16.

[19] Reith, C.C. and Salerni, E., 1997, "Landfill mining for resource recovery", Presentation at the Air and Waste Management Association's 90th Annual Meeting \& Exhibition, June 8-13, 1997, Toronto, Ontario, Canada.

[20] Yokoyama, K., Onda, T., Kashiwakura, S. \& Nagasaka, T. 2006, "Waste input-output analysis on "landfill mining activity"", Materials Transactions, vol. 47, no. 10, pp. 2582-2587.

[21] Carter, R.A. 1989, "Landfills can be profitable", Rock products, vol. 92, no. 12, pp. 5862.

[22] Spencer, R. 1990, "Landfill space reuse", Biocycle, vol. 31, no. 2, pp. 30-33.

[23] Hogland, W., Marques, M. \& Nimmermark, S. 2004, "Landfill mining and waste characterization: a strategy for remediation of contaminated areas", Journal of Material Cycles and Waste Management, vol. 6, no. 2, pp. 119-124.

[24] Joseph, K., Esakku, S. \& Nagendran, R. 2007, "Mining of compost from dumpsites and bioreactor landfills", International Journal of Environmental Technology and Management, vol. 7, no. 3-4, pp. 317-325.

[25] Gordon, R.B., Bertram, M. \& Graedel, T.E. 2006, "Metal stocks and sustainability", Proceedings of the National Academy of Sciences of the United States of America, vol. 103, no. 5, pp. 1209-1214.

[26] Wang, T., Müller, D.B. \& Graedel, T.E. 2007, "Forging the anthropogenic iron cycle", Environmental Science and Technology, vol. 41, no. 14, pp. 5120-5129.

[27] Wittmer, D., Lichtensteiger, T. \& Wittmer, D. 2007, "Exploration of urban deposits: Long-term prospects for resource and waste management", Waste Management and Research, vol. 25, no. 3, pp. 220-226.

[28] Reck, B., Bertram, M., Müller, D.B. \& Graedel, T.E. 2006, "Multilevel anthropogenic cycles of copper and zinc: A comparative statistical analysis", Journal of Industrial Ecology, vol. 10, no. 1-2, pp. 89-110.

[29] Johnson, J., Jirikowic, J., Bertram, M., Van Beers, D., Gordon, R.B., Henderson, K., Klee, R.J., Lanzano, T., Lifset, R., Oetjen, L. \& Graedel, T.E. 2005, "Contemporary anthropogenic silver cycle: A multilevel analysis", Environmental Science and Technology, vol. 39, no. 12, pp. 4655-4665. 